\title{
Premarital Sexual Practice and Its Predictors Among Preparatory School Students Living with and Without Parents in Hossana Town, Southern Ethiopia
}

\author{
Alemu Earsido Addila, ${ }^{1, ~ *, ~ N e b i y u ~ D e r e j e ~ A b e b e ~}{ }^{1}$, Wondwosen Abebe ${ }^{2}$, Ermias Abera Turuse $^{1}$ \\ ${ }^{1}$ Department of Public Health, College of Medicine and Health Sciences, Wachemo University, Hossana, Ethiopia \\ ${ }^{2}$ Department of Microbiology, College of Medicine and Health Sciences, University of Gondar, Gondar, Ethiopia
}

\section{Email address:}

alexisersid@gmail.com (A. E. Addila),neba.jahovy@gmail.com (N. D. Abebe), wondisweet@gmail.com (W. Abebe), ermiasturuse@gmail.com (E. A. Turuse)

*Corresponding author

\section{To cite this article:}

Alemu Earsido Addila, Nebiyu Dereje Abebe, Wondwosen Abebe, Ermias Abera Turuse. Premarital Sexual Practice and Its Predictors Among Preparatory School Students Living with and Without Parents in Hossana Town, Southern Ethiopia. Science Journal of Public Health. Vol. 8, No. 3, 2020, pp. 63-71. doi: 10.11648/j.sjph.20200803.11

Received: February 10, 2020; Accepted: February 24, 2020; Published: May 29, 2020

\begin{abstract}
Globally, pre-marital sexual activities among adolescents have been reported to be increasing. Many studies in Sub- Saharan Africa, including Ethiopia, had reported that there were increasing premarital sexual activities among adolescents and youths. Besides, they are risk-takers who are more likely to make decisions about the future without adequately considering the consequences. The study aimed to assess the premarital sexual practice and its predictors among preparatory school students living with and without parents in Hossana Town, Southern Ethiopia. An institution-based comparative crosssectional study design was carried out using a self-administered questionnaire. The sample size was determined by using EPI INFO version 3.5.3 software of two population proportions. The sample size for students who were living without parents and with parents was 202 and 404, respectively, and the overall sample size including a $10 \%$ non-response rate was 606 . The predictors of pre-marital sexual debut were assessed using bivariate and multivariable logistic regression. The magnitude of pre-marital sexual practice was $105(27 \%)$ and $76(39 \%)$ among students who were living with and without their parents, respectively. Watching pornography videos [AOR $=4.9,95 \% \mathrm{CI}: 2.4,10.2]$, discussing about sexual issues with their friends or peers [AOR $=3.5,95 \%$ CI: 1.72, 7.15], drinking alcohol [AOR=6.62, 95\% CI: 2.26, 19.36], and educational status of the father were predictors for students who live with their parents while discussing about sex with [AOR=5, 95\% CI: 1.12, 5.6], watching pornography videos $[\mathrm{AOR}=2.7,95 \% \mathrm{CI}: 1.16,6.07]$ drinking alcohol [AOR $=6.0,95 \% \mathrm{CI}: 1.2,29.7]$ were also predictors for students who live without their parents. The prevalence of pre-marital sexual practice was high in both groups; especially students who live without their parents. Thus, public health interventions should predominately focus on behavioral, social, and environmental factors of pre-marital sexual practices.
\end{abstract}

Keywords: Living with or Without Parents, Premarital Sex, Preparatory Schools

\section{Introduction}

According to the World health organization (WHO) definition, adolescents are individuals in the age group 10-19 years old and youth are 15-24 years age group [1]. Youths highly concern with physical and sexual attractiveness, have an increased interest in the opposite sex, and are frequently changing relationships. In addition, they are risk-takers who are more likely to make decisions about the future without adequately considering the consequences [2]. Globally, premarital sexual activities among adolescents have been reported to be increasing [3]. Many studies in Sub- Saharan Africa had reported that there were increasing premarital sexual activities among adolescents and youths $[4,5]$. Youths often face strong peer, social and cultural pressure to engage in premarital sex. Significant numbers of adolescents are involved in sexual activities at an early age $[3,6]$. Previous studies documented that adolescents engage in premarital sex 
with insufficient knowledge of reproductive health, family planning, and the small proportion of use contraceptive [7-9].

According to the results of various studies were conducted in Ethiopian preparatory or high schools and universities, pre-marital sexual practice varies from $11.9 \%$ to $54.3 \%$ [7, 10-16]. In similar studies, being male, chewing chat, peer pressure, drinking alcohol, watching pornography film were factors statistically associated with the pre-marital sexual practice. The result of these findings showed that there is inconsistency among different settings in Ethiopia. In addition, adolescents who experienced peer pressure from their friends were found more likely to involve in premarital sexual practice than those adolescents who didn't experience peer pressure from their friends. Youth who begin early sexual activity are more likely to be exposed to high-risk sex, often having multiple partners. Risky sexual activity results not only in exposing youths to STIs and HIV/AIDS, but also unwanted pregnancy in females, which may cause serious health, social, economic problems, and a failure to complete their education $[17,18]$.

In Ethiopian, due to the absence of preparatory schools in the rural and semi-urban settings, many students live in rental houses with friends or with their relatives. They often take advantage of autonomy from direct parental regulation and guidance to express their freedom by initiating sexual activity without adequate protection. Indeed, living far away from their parents give a high level of personal freedom and social interactions, this offers an opportunity for a high level of sexual networking. Especially, in the study area, a number of students come from the rural environment and are living far apart from their families. Consequently, there is an information gap regarding risky sexual behaviors [19]. Access to healthcare and sources of information, education, and support also vary extensively [9, 20]. The key issues, barriers, and challenges, as well as potential solutions, can be identified across the county [21]. It is crucial to identify the determinants of pre-marital sexual activity to inform policymakers and local program managers. However, preparatory school students' premarital sexual practice and its predictors were not dealt with in-depth within the study area.

Therefore, studying premarital sexual practices and its predictors is an essential issue for policymakers as well as for organizations that work in the area. Thus, this study tried to identify premarital sexual practices and associated factors among preparatory school youths in the study area.

\section{Methods}

\subsection{Study Design and Setting}

An institution based comparative cross sectional study design was employed from 19 October to 17 November 2018. The study was conducted in Hossana town, Southern Ethiopia, which is located $230 \mathrm{~km}$ from Addis Ababa, capital city of Ethiopia. In the town, there are two governmental and two private preparatory schools and the total number of students were 3626 and 1776, respectively [22].

\subsection{Sample Size Determination Sampling Procedure}

All preparatory school students who were residing and learning in the study area were considered as source population while those respondents of preparatory school youths aged 15 to 24 years who were enrolled as regular daytime students in the study period and available during data collection period were taken as a study population.

The sample size was determined by using EPI INFO version 3.5.3 soft ware of two population proportion formulas by assumption of $95 \%$ confidence interval, $80 \%$ power and by considering "Pocket money" as a factor for pre-marital sexual activity to bring difference in two populations from the research conducted at Eastern Hararge zone school students.

$$
\mathrm{n} 1=\frac{\mathrm{z} \alpha \sqrt{\left(1+\frac{1}{\mathrm{r}}\right) \mathrm{p}(1-\mathrm{p})}+\sqrt[\mathrm{z} \beta]{\mathrm{p} 1(1-\mathrm{p} 1)+\frac{\mathrm{p} 2(1-\mathrm{p} 2)}{\mathrm{r}}} 2}{\left(p_{1}-p_{2}\right)^{2}}=\frac{p_{1}+r p_{2}}{1+r}
$$

Where: - $\mathrm{n}_{1}=$ sample size for students living without parents and $n_{2}=$ sample size for students living with parents, then students living without parents to students living with parents ratio will be $\mathrm{r}=\frac{\mathrm{n} 2}{\mathrm{n} 1}=2$

$\mathrm{P}=$ Pooled estimate of $\mathrm{p} 1$ and $\mathrm{p} 2$

$\mathrm{P}_{1}=29 \%$, the proportion of students who were having pocket money for students living without parents

$\mathrm{P}_{2}=18 \%$, the proportion of students who were having pocket money for students living with parents (expected frequency of exposure among students who were living with parents). The sample size for students who were living without parents and with parents were 202 and 404, respectively and overall sample size including $10 \%$ non response rate was 606 .

\subsection{Sampling Procedure}

There were three preparatory schools in the town and all of them were included in the study. The total number of the students was 5402; of these 2859 and 2543 were living without and with parents, respectively.

Based on this, a sampling frame that enlists all students was prepared at each school and section. The number of study units to be sampled from each school and section by using proportional allocation to the number of students in each section and systematic random sampling was applied to select each study subject. A first student in each section was selected by the simple random sampling method. The next student in the section was identified systematically by every sampling interval. Finally, by using a systematic random sampling method the study subjects were selected.

Study variables: Premarital sexual practice was a dependent variable, whereas age, sex of the student, religion, ethnicity, pocket money, educational status of the parents, family income, condom use, chewing khat, alcohol drinking, smoking cigarette, and watching pornographic movies were independent variables. 


\subsection{Operational Definitions}

Premarital sex: - doing sexual intercourse with before marriage

Living with parents: - living with one or both parents

Living without parents: - living alone or with anyone except parents

\subsection{Data Collection Procedures}

Data was collected by self-administered using a structured and pre-tested questionnaire. The questionnaire was first prepared in English and then was translated into Amharic (a local language) to suit local applicability and finally, back to English to ensure its consistency. These questionnaires were adapted from different kinds of literature developed for similar purposes by considering the local situation of the study subjects. The Amharic version questionnaire was pretested for clarity or ambiguity. Based on the findings of pre-testing, the questions with certain ambiguity were modified to ensure validity and then the corrected questionnaires were distributed to the data collectors to collect the data. Data collectors and supervisors were trained for two consecutive days on the points on how to take informed consent, how to approach study participants, ethical procedure, and the objectives of the study.

\subsection{Data Management and Analysis}

All the questionnaires were entered, edited, coded and cleaned in the Epi-info version 3.5.3 and exported to SPSS version 24 software packages for analysis. The data were analyzed using logistic regression (bivariate and multivariable) to determine the effect of various factors on the outcome variable and to control the confounding effect. The results were presented in the form of tables, figures, and text using frequencies and summary statistics such as mean, standard deviation and percentage to describe the study population in relation to relevant variables. The degree of association between independent and dependent variables was assessed using odds ratio, 95\% confidence interval and $p$-value $<0.05$ to be considered as significant.

\section{Ethical Consideration}

Ethical clearance and supportive letter to undertake the study was obtained from the Wachemo University Ethical review board and the formal letter of permission was taken from Hossana town educational office. All the study participants were informed about the objective and importance of the study and their verbal consents were obtained before commencing data collection. They were also informed about their right of not participating in the study at any time.

\section{Results}

\subsection{Socio-demographic Characteristics of the Study Participants}

A total of 576 students participated in the study with a response rate of $95 \%$. Of these, 192 and 384 were living without and with their parents, respectively. Among these, 209 males and 175 females were living with their parents and, 102 males and 90 females living without parents. The majority, $255(66 \%)$ and $164(85 \%)$ of the students were living with and without parents of age greater than 18 years, respectively. With regard to respondents religious, more than half of them 247 (64\%) living with their parents and 117 (61\%) living without parents were protestants. Pertaining to the ethnicity of the study participants, majority $228(59 \%)$ and $126(66 \%)$ who were living with and without their parents were Hadiya, respectively (Table 1).

Table 1. Socio-demographic characteristics of preparatory school students in Hossana town, Southern Ethiopia, $2018(n=576)$.

\begin{tabular}{|c|c|c|}
\hline \multirow{2}{*}{ Variables } & \multicolumn{2}{|l|}{ Living } \\
\hline & With parents & Without parents \\
\hline \multicolumn{3}{|l|}{ Sex } \\
\hline Male & $209(54 \%)$ & $102(53 \%)$ \\
\hline Female & $175(46 \%)$ & $90(47 \%)$ \\
\hline \multicolumn{3}{|l|}{ Age } \\
\hline$<18$ & $129(34 \%)$ & $28(15 \%)$ \\
\hline$\geq 18$ & $255(66 \%)$ & $164(85 \%)$ \\
\hline \multicolumn{3}{|l|}{ Religion } \\
\hline Protestant & $247(64 \%)$ & $117(61 \%)$ \\
\hline Orthodox & $63(16 \%)$ & $31(16 \%)$ \\
\hline Muslim & $39(10 \%)$ & $13(7 \%)$ \\
\hline Catholic & $19(5 \%)$ & $20(10 \%)$ \\
\hline Others & $16(4 \%)$ & $11(6 \%)$ \\
\hline \multicolumn{3}{|c|}{ Attending religious services } \\
\hline Every day & $70(18 \%)$ & $27(14 \%)$ \\
\hline Once per week & $112(29 \%)$ & $73(38 \%)$ \\
\hline 2-3 times per week & $176(46 \%)$ & $77(40 \%)$ \\
\hline Not attend at all & $26(7 \%)$ & $15(8 \%)$ \\
\hline \multicolumn{3}{|l|}{ Ethnicity } \\
\hline Hadiya & $228(59 \%)$ & $126(66 \%)$ \\
\hline Amhara & $42(11 \%)$ & $17(9 \%)$ \\
\hline Kanbata & $56(15 \%)$ & $21(10 \%)$ \\
\hline Silte & $16(4 \%)$ & $9(5 \%)$ \\
\hline Gurage & $21(5 \%)$ & $6(3 \%)$ \\
\hline Others* & $20(5 \%)$ & $13(7 \%)$ \\
\hline \multicolumn{3}{|l|}{ Reading with friends } \\
\hline Yes & $212(55 \%)$ & $118(61 \%)$ \\
\hline No & $172(45 \%)$ & $74(39 \%)$ \\
\hline \multicolumn{3}{|c|}{ Monthly pocket money (ETB) } \\
\hline$<100$ & $196(51 \%)$ & $78(41 \%)$ \\
\hline $100-300$ & $123(32 \%)$ & $60(31 \%)$ \\
\hline $301-500$ & $44(13 \%)$ & $29(15 \%)$ \\
\hline $501-700$ & $12(3 \%)$ & $13(7 \%)$ \\
\hline$>700$ & $9(2 \%)$ & $12(6 \%)$ \\
\hline
\end{tabular}

\subsection{Parental Socio-demographic Characteristics of Respondents}

More than three-fourth 317 (83\%) parents were living in the urban among students who were living with their parents while almost half $108(56 \%)$ of parents were dwelling in rural among students who were living without their parents. 
Two-hundred six (54\%) and 50 (26\%) fathers had diplomas and above among students living with and without their parents, respectively. Regarding the occupational status of the mothers, around half $184(48 \%)$ and two-third $119(62 \%)$ of the students' mothers were housewives among students who were living with and without parents, respectively.

Table 2. Parental socio-demographic characteristics of preparatory school students in Hossana town, southern Ethiopia, 2018 ( $n=576$ ).

\begin{tabular}{lll}
\hline \multirow{2}{*}{ Variables } & Living & \\
\cline { 2 - 3 } & With parents & Without parents \\
\hline Residences & $317(83 \%)$ & $84(44 \%)$ \\
Rurban & $67(17 \%)$ & $108(56 \%)$ \\
Educational status of fathers & & \\
Illiterate (can't read or write) & $21(5 \%)$ & $30(16 \%)$ \\
Primary (1-8) & $70(18 \%)$ & $67(35 \%)$ \\
Secondary (9-12) & $87(23 \%)$ & $45(23 \%)$ \\
Diploma and above & $206(54 \%)$ & $50(26 \%)$ \\
Educational status of mothers & & \\
Illiterate (can't read or write) & $54(14 \%)$ & $44(23 \%)$ \\
Primary (1-8) & $105(27 \%)$ & $81(42 \%)$ \\
Secondary (9-12) & $108(28 \%)$ & $36(19 \%)$ \\
Diploma and above & $117(30 \%)$ & $31(16 \%)$ \\
Occupation of fathers & & \\
Merchant & $118(31 \%)$ & $63(33 \%)$ \\
Government worker & $172(45 \%)$ & $60(31 \%)$ \\
NGO worker & $48(13 \%)$ & $21(11 \%)$ \\
Farmer & $37(10 \%)$ & $40(21 \%)$ \\
Others & $9(2 \%)$ & $8(4 \%)$ \\
Occupation of mothers & $73(19 \%)$ & $22(11 \%)$ \\
Merchant & &
\end{tabular}

\begin{tabular}{lll}
\hline \multirow{2}{*}{ Variables } & Living \\
\cline { 2 - 3 } & With parents & Without parents \\
\hline Government worker & $88(23 \%)$ & $32(17 \%)$ \\
NGO worker & $33(9 \%)$ & $15(8 \%)$ \\
Housewife & $184(48 \%)$ & $119(62 \%)$ \\
Others & $6(2 \%)$ & $4(2 \%)$ \\
Marital status of parents & & \\
Living together & $326(85 \%)$ & $142(74 \%)$ \\
Separated & $38(10 \%)$ & $34(18 \%)$ \\
Not formally married & $20(5 \%)$ & $16(8 \%)$ \\
Family monthly income & & \\
Less than 2000 & $35(9 \%)$ & $29(15 \%)$ \\
2001-4000 & $75(19 \%)$ & $33(17 \%)$ \\
$4001-6000$ & $110(29 \%)$ & $53(28 \%)$ \\
$6001-8000$ & $68(18 \%)$ & $35(15 \%)$ \\
Above 8000 & $47(12 \%)$ & $20(10 \%)$ \\
I don't know & $49(13 \%)$ & $22(11 \%)$ \\
\hline
\end{tabular}

\subsection{Premarital Sexual Practice of Preparatory School Students in Hossana Town, Southern Ethiopia, 2018}

The prevalence of premarital sexual practice was $105(27.3 \%)$ (95\% CI: 22.9\%-32.1\%) and 76 (39.6\%) (95\% CI: 31.8\%-47\%) living with and without their living parents, respectively. Among the study respondents, 170 (44\%) living with their parents and 83 (43\%) living without their parents had boy/girlfriends. Almost more than half, 55 (56\%) and 32 (49\%) living with and without their parents watched pornography films once a week, respectively. Most students practiced sexual intercourse between 15-18 years for the first time.

Table 3. Premarital sexual practice of preparatory school students in Hossana Town, Southern Ethiopia, 2018.

\begin{tabular}{|c|c|c|c|c|}
\hline \multirow{3}{*}{ Variables } & \multicolumn{4}{|c|}{ Premarital sexual practice } \\
\hline & \multicolumn{2}{|c|}{ Living with parents } & \multicolumn{2}{|c|}{ Living without parents } \\
\hline & Yes & No & Yes & No \\
\hline \multicolumn{5}{|c|}{ Having a boy/girl friend } \\
\hline Yes & $67(17.4 \%)$ & $103(26.8 \%)$ & $46(24 \%)$ & $37(19.3 \%)$ \\
\hline No & $38(9.9 \%)$ & $176(45.8 \%)$ & $30(15.6 \%)$ & $79(41 \%)$ \\
\hline \multicolumn{5}{|c|}{ Watching pornography films } \\
\hline Yes & $53(13.8 \%)$ & $41(10.7 \%)$ & $45(23.4 \%)$ & $20(10.4 \%)$ \\
\hline \multicolumn{5}{|c|}{ Discussing about sex with friends } \\
\hline Yes & $59(15.4 \%)$ & $67(17.4 \%)$ & $53(27.6 \%)$ & $25(13 \%)$ \\
\hline No & $46(12 \%)$ & $212(55.2 \%)$ & $23(12 \%)$ & $91(47.4 \%)$ \\
\hline \multicolumn{5}{|c|}{ Discussing about sex with parents } \\
\hline Yes & $19(5 \%)$ & $28(7.3 \%)$ & $17(8.8 \%)$ & $13(6.8 \%)$ \\
\hline No & $86(22.4 \%)$ & $251(65.4 \%)$ & $59(30.7 \%)$ & $103(53.6 \%)$ \\
\hline \multicolumn{5}{|c|}{ Number of sexual partners $(n=132)$} \\
\hline Three and above & $17(23 \%)$ & & $11(19 \%)$ & \\
\hline \multicolumn{5}{|c|}{ Use of condom at first sex $(n=181)$} \\
\hline Yes & $27(26 \%)$ & & $24(32 \%)$ & \\
\hline No & $78(74 \%)$ & & $52(68 \%)$ & \\
\hline \multicolumn{5}{|c|}{ Frequency of condom use $(n=181)$} \\
\hline No use & $37(35 \%)$ & & $25(33 \%)$ & \\
\hline Sometimes & $45(43 \%)$ & & $35(46 \%)$ & \\
\hline Always & $23(22 \%)$ & & $16(21 \%)$ & \\
\hline \multicolumn{5}{|c|}{ Peer pressure for sex $(n=177)$} \\
\hline Yes & $33(32 \%)$ & & $18(24 \%)$ & \\
\hline No & $70(68 \%)$ & & $56(76 \%)$ & \\
\hline \multicolumn{5}{|c|}{ Alcohol use $(n=448)$} \\
\hline Yes & $28(9.3 \%)$ & $3(1 \%)$ & $9(6 \%)$ & $1(0.7 \%)$ \\
\hline No & $55(18.3 \%)$ & $215(71.4 \%)$ & $62(42.2 \%)$ & $7(51 \%)$ \\
\hline
\end{tabular}




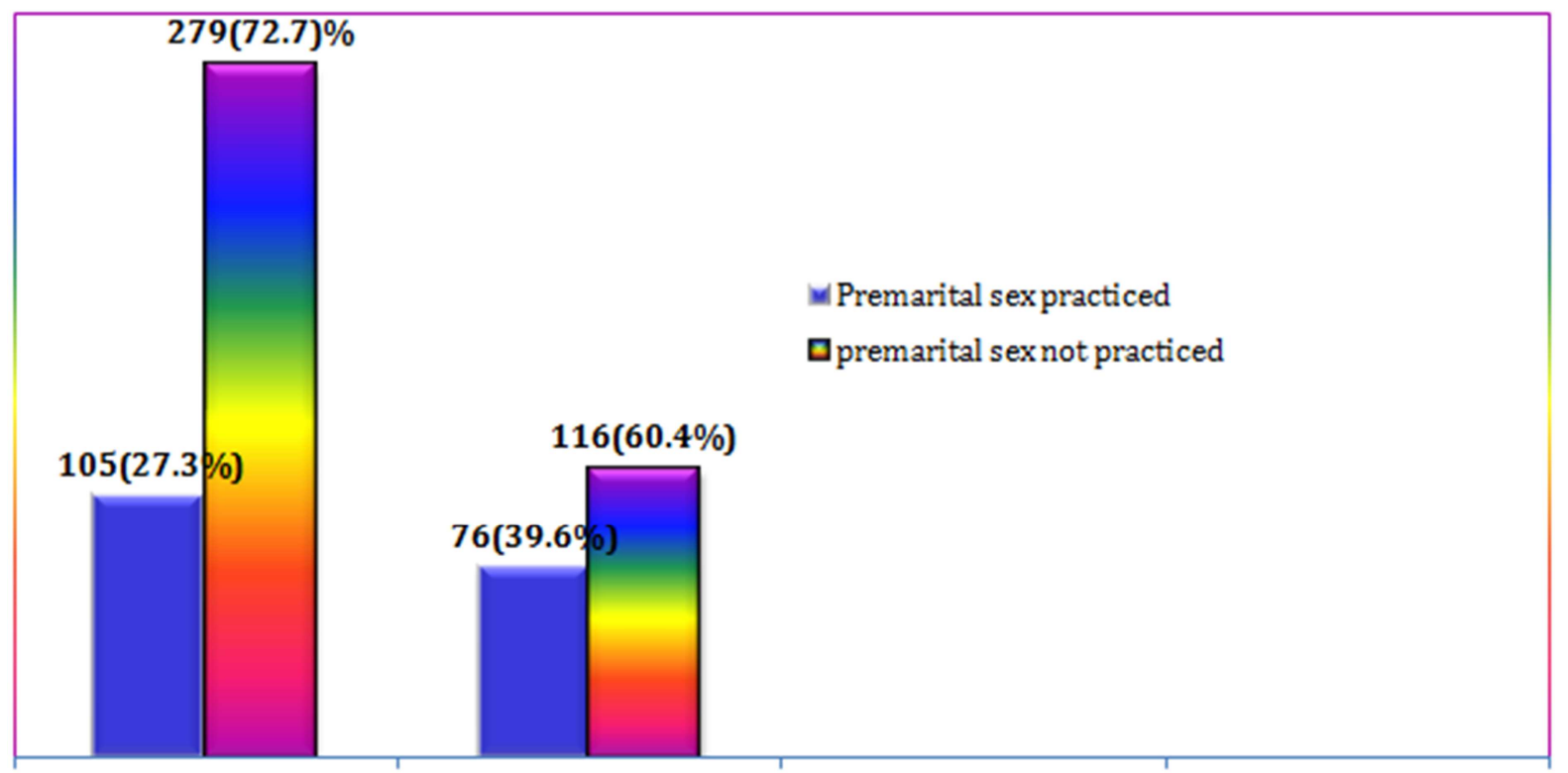

Living with parents Living without parents

Figure 1. Premarital sexual practice of preparatory school students, Hossana town, Southern Ethiopia, 2018.

\subsection{Predictors of Premarital Sexual Practice Among Preparatory School Students Who Were Living with Parents in Hossana Town, Southern Ethiopia, 2018}

Variables which could persist in having a determinant effect in the multivariable analyses were watching pornography videos, educational level of fathers, discuss about sex with their friends and alcohol drinking. Students had watched pornography videos were five times more likely to practice premarital sex than their counterparts $[\mathrm{AOR}=4.9$, 95\% CI: 2.4, 10.2]. When the educational status of the respondents' fathers increased, the premarital sex practice of students decreased. Respondents' fathers with educational level illiterate, primary (1-8) were $[\mathrm{AOR}=5.3,95 \% \mathrm{CI}: 1.2$, 26.5], $[\mathrm{AOR}=6.95,95 \% \mathrm{CI}: 1.44,33.43]$ and $[\mathrm{AOR}=13.44$, 95\% CI: 2.98, 60.6] more likely to practice premarital sex than secondary (9-12) diploma and above, respectively. Students who discussed about sex with their friends/peers were almost four times more likely to practice premarital sex than those who didn't discuss $[\mathrm{AOR}=3.5,95 \% \mathrm{CI}: 1.72$, 7.15]. Students dirked alcohol seven times more likely to exercise premarital sex than those who didn't drink [AOR=6.62, 95\% CI: 2.26, 19.36] (Table 4).

Table 4. Predictors of premarital sexual practice among preparatory school students who were living with parents in Hossana town, 2018.

\begin{tabular}{|c|c|c|c|c|c|}
\hline \multirow{2}{*}{ Variables } & \multicolumn{2}{|c|}{ Premarital sex } & \multirow{2}{*}{$\begin{array}{l}\text { Crude OR (95\% } \\
\text { CI) }\end{array}$} & \multirow{2}{*}{$\operatorname{AOR}(95 \% \mathrm{CI})$} & \multirow{2}{*}{ P-value } \\
\hline & Yes No (\%) & No No (\%) & & & \\
\hline \multicolumn{6}{|l|}{ Sex } \\
\hline Male & $66(63)$ & $143(51)$ & $1.61(1.06,2.55)$ & $1.25(0.59,2.9)$ & \\
\hline Female & $39(37)$ & $136(49)$ & 1 & 1 & \\
\hline \multicolumn{6}{|c|}{ Attending religious services $(n=384)$} \\
\hline Every day & $14(13)$ & $56(20)$ & 1 & 1 & \\
\hline Once per week & $34(33)$ & $78(28)$ & $3.67(1.5,8.9)$ & $0.65(0.23,1.8)$ & \\
\hline Not attend at all & $16(15)$ & $10(4)$ & $6.4(2.4,17.1)$ & $1.3(0.4,4.5)$ & \\
\hline \multicolumn{6}{|l|}{ Monthly pocket money (ETB) } \\
\hline$<100$ & $48(47)$ & $148(53)$ & 1 & 1 & \\
\hline $100-300$ & $30(29)$ & $93(33)$ & $10.85(2.14,55)$ & $4.6(0.57,37.9)$ & \\
\hline $301-500$ & $13(12)$ & $31(11)$ & $8.35(1.53,45.67)$ & $1.8(0.18,17.00)$ & \\
\hline $501-700$ & $7(6)$ & $5(2)$ & $2.5(0.36,17.5)$ & $1.06(0.09,13.17)$ & \\
\hline$>700$ & $7(6)$ & $2(1)$ & $10.79(2.17,53.7)$ & $3.5(0.46,26.8)$ & \\
\hline \multicolumn{6}{|l|}{ Residence of parents } \\
\hline Urban & $81(77)$ & $236(85)$ & 1 & 1 & \\
\hline Rural & $24(33)$ & $43(15)$ & $1.63(0.93,2.85)$ & $1.5(0.5,3.3)$ & \\
\hline \multicolumn{6}{|l|}{ Educational status of fathers } \\
\hline Illiterate (can't read or write) & $10(9)$ & $11(4)$ & $3.45(1.37,8.65)$ & $5.3(1.2,26.4)$ & 0.032 \\
\hline Primary $(1-8)$ & $23(22)$ & $47(17)$ & $1.86(0.7,5)$ & $6.95(1.44,33.43)$ & 0.016 \\
\hline Secondary (9-12) & $29(28)$ & $58(21)$ & $1.82(0.69,4.77$ & $13.44(2.98,60.6)$ & 0.001 \\
\hline Diploma and above & $43(41)$ & $163(58)$ & 1 & 1 & \\
\hline Educational level of mothers & & & & & \\
\hline
\end{tabular}




\begin{tabular}{|c|c|c|c|c|c|}
\hline \multirow{2}{*}{ Variables } & \multicolumn{2}{|c|}{ Premarital sex } & \multirow{2}{*}{$\begin{array}{l}\text { Crude OR (95\% } \\
\text { CI) }\end{array}$} & \multirow{2}{*}{$\operatorname{AOR}(95 \% \mathrm{CI})$} & \multirow{2}{*}{ P-value } \\
\hline & Yes No (\%) & No No (\%) & & & \\
\hline Illiterate (can't read or write) & $18(18)$ & $36(13)$ & $2.29(1.09,4.78)$ & $0.9(0.16,4.8)$ & \\
\hline Primary $(1-8)$ & $33(31)$ & $72(26)$ & $1.09(0.54,2.2)$ & $0.5(0.12,2.4)$ & \\
\hline Secondary $(9-12)$ & $33(31)$ & $75(27)$ & $1.14(0.57,2.3$ & $0.86(0.18,4.0)$ & \\
\hline Diploma and above & $21(20)$ & $96(34)$ & 1 & 1 & \\
\hline \multicolumn{6}{|l|}{ Having boy/girl friend } \\
\hline Yes & $67(64)$ & $103(37)$ & $3.0(1.89,4.8)$ & $0.7(0.35,1.39)$ & \\
\hline No & $38(36)$ & $176(63)$ & 1 & 1 & \\
\hline \multicolumn{6}{|l|}{ Watching pornography videos } \\
\hline Yes & $53(50)$ & $41(15)$ & $5.92(3.6,9.82)$ & $4.93(2.4,10.2)$ & $<0.001$ \\
\hline No & $52(50)$ & $238(85)$ & 1 & 1 & \\
\hline \multicolumn{6}{|c|}{ Discuss about sex with their friends } \\
\hline Yes & $59(56)$ & $67(24)$ & $4(2.53,6.52)$ & $3.5(1.72,7.15)$ & $<0.001$ \\
\hline No & $46(44)$ & $212(76)$ & 1 & 1 & \\
\hline \multicolumn{6}{|c|}{ Discuss about sex with their parents } \\
\hline Yes & $19(18)$ & $28(10)$ & $1.98(1.05,3.73)$ & $1.36(0.46,4.00)$ & \\
\hline \multirow{2}{*}{\multicolumn{6}{|c|}{ Khat chewing }} \\
\hline & & & & & \\
\hline Yes & $17(22)$ & $3(1.5)$ & $19.4(5.5,68.47)$ & $1.5(0.33,6.95)$ & \\
\hline No & $59(88)$ & $202(98.5)$ & 1 & 1 & \\
\hline \multicolumn{6}{|l|}{ Drinking alcohol } \\
\hline Yes & $28(34)$ & $3(2)$ & $36.5(10.7,12.4)$ & $6.62(2.26,19.38)$ & 0.001 \\
\hline No & $55(66)$ & $125(98)$ & 1 & 1 & \\
\hline \multicolumn{6}{|l|}{ Smoking cigarette } \\
\hline Yes & $15(19)$ & $8(4)$ & $6.56(2.66,16.2)$ & $1.01(0.2,6.36)$ & \\
\hline No & $62(81)$ & $217(96)$ & 1 & 1 & \\
\hline
\end{tabular}

\subsection{Predictors of Premarital Sexual Practice Among Preparatory School Students Who Were Living without Parents in Hossana Town, Southern Ethiopia, 2018}

There were three variables had a determinant effect among many. Students had watched pornography videos were three times more likely to practice premarital sex than their counterparts [AOR=2.7, 95\% CI: $1.16,6.07]$. Students who discussed about sex with their friends/peers were almost five times more likely practiced premarital sex than who didn't discuss $[\mathrm{AOR}=5,95 \% \mathrm{CI}: 1.12,5.6]$ and Students drank alcohol six times more likely to exercise premarital sex than who didn't drink [AOR=6, 95\% CI: 1.2, 29.7] (Table 5).

Table 5. Predictors of premarital sexual practice among preparatory school students who were living without parents in Hossana town, 2018.

\begin{tabular}{|c|c|c|c|c|c|}
\hline \multirow{2}{*}{ Variables } & \multicolumn{2}{|c|}{ Premarital sex } & \multirow{2}{*}{$\begin{array}{l}\text { Crude OR (95\% } \\
\text { CI) }\end{array}$} & \multirow{2}{*}{$\operatorname{AOR}(95 \%$ CI $)$} & \multirow{2}{*}{ P-value } \\
\hline & Yes No (\%) & No No (\%) & & & \\
\hline \multicolumn{6}{|c|}{ Residence of parents } \\
\hline Urban & $24(29)$ & $52(48)$ & 1 & 1 & \\
\hline Rural & $60(71)$ & $56(52)$ & $2.32(1.27,4.3)$ & $1.45(0.62,3.4 .3)$ & \\
\hline \multicolumn{6}{|c|}{ Having boy/girl friend } \\
\hline Yes & $46(53)$ & $37(32)$ & $3.3(1.8,6)$ & $1.5(0.67,3.5)$ & \\
\hline No & $30(47)$ & $79(68)$ & 1 & 1 & \\
\hline Yes & $45(59)$ & $20(17)$ & $7(3.59,13.54)$ & $2.7(1.16,6.07)$ & 0.021 \\
\hline No & $31(41)$ & $96(83)$ & 1 & 1 & \\
\hline \multicolumn{6}{|c|}{ Discuss about sex with their friends } \\
\hline Yes & $53(70)$ & $25(22)$ & $8.4(4.34,16.23)$ & $5(1.12,5.6)$ & 0.026 \\
\hline No & $23(30)$ & $91(78)$ & 1 & 1 & \\
\hline \multicolumn{6}{|c|}{ Discuss about sex with their parents } \\
\hline Yes & $17(22)$ & $13(11)$ & $2.28(1.04,5.03)$ & $1.7(0.47,6.13)$ & \\
\hline Yes & $13(21)$ & $2(2)$ & $10.66(2.3,48.2)$ & $6.0(1.2,29.7)$ & 0.03 \\
\hline No & $50(79)$ & $82(88)$ & 1 & 1 & \\
\hline
\end{tabular}

\section{Discussion}

Youths have an increased interest in the opposite sex, highly concerned with physical and sexual attractiveness, and are frequently changing relationships. Besides, they are risk- takers who are more likely to make decisions about the future without adequately considering the consequences [2]. In this study, the prevalence of premarital sex was found to be $27 \%$ and $39 \%$ among preparatory school students who were living with and without parents, respectively. Students lived with relatives, friends or lonely instead of their biological parents, 
and thus lack familial control and liberal lifestyles, and then more exposed to premarital sex. This result was slightly higher than studies done in west Gojjam zone (19\%), in Nekemte town (21.5\%), Eastern Ethiopia (24.8\%), Northern Ethiopia (21.1\%) and Kolfe Keraniyo sub-city in Addis Ababa (19.8\%)[7, 11, 13, 23, 24], whereas it was lower than from studies conducted in Jimma town (42.1\%) [25], Madawalabu University (42.7\%), Yabello town, Southern Ethiopia (71.9\%), Bale Zone (51.9\%) [4, 20, 26]. This discrepancy may be due to the difference in socio-cultural and schooling status among the study participants. Among students who were living without their biological parents $77 \%$ of them didn't use condom sometimes or at all during sexual activity, $50 \%$ of the female students encountered with abortion, $86 \%$ of the khat chewers, $90 \%$ of the alcohol users and $75 \%$ of the cigarette smokers engaged in premarital sex. On the other hand, among students who were living with their biological parents $73 \%$ of them didn't use condom sometimes or at all during sexual activity, $22 \%$ of the female students encountered with abortion, $71 \%$ of the khat chewers $54 \%$ of the alcohol users $50 \%$ of the cigarette smokers engaged in premarital sex. Living without biological parents attributes for risky sexual behavior [27]. Watching pornographic movies play a significant role in the commencement of earlier sexual practice which was consistent with the study done in Debre Berhan University [7, 14, 28, 29]. A possible explanation might be because of the potential stimulating effect on sexual desire and its power to increase comprehended pleasure from sexual intercourse.

Alcohol use was one of the most powerful predictors of premarital sexual activity among both living with and without parents in this study and this was in line with the studies done in Gamo Gofa, South West Ethiopia [30] and Jimma Town [25]. Father's educational status was one of the associated factors for premarital sex for students living with parents but not for living without parents. When the educational level of the fathers increases, students' premarital sexual activity decreases. This might be due to more educated fathers have good knowledge about the risk of premarital sex and advise their sons/daughters. Youth face a higher risk of complications and death as a result of unwanted pregnancy than older women. Healthcare workers have an important role to play in the advancement and commitment to promoting adolescent sexual and reproductive health services. Addressing the global problems of adolescent health is critical to the future of a country's health and must be led by those at the front line healthcare workers.

\section{Limitation}

The major limitation of this study was the nature of the cross-sectional study which may not explain the temporal relationship between the outcome variable and some explanatory variables. The study topic by itself assesses personnel and sensitive issues related to sexuality which might have caused social desirability bias.

\section{Conclusion}

Many students are recently engaging in premarital sexual activities due to a number of reasons. The prevalence of premarital sexual practice in our study was high in both groups compared to other studies; especially students who live without their parents. Thus, public health interventions should predominately focus on behavioral, social, and environmental factors of the pre-marital sexual practices. Preparatory schools should avail or launch different antisubstance use clubs and appropriate guidance in the schools. Furthermore, parents have to follow their son/daughter day to day activities (i.e. either he/she is properly learning and attending class or not). Besides, Education, health bureaus, and healthcare workers should work cooperatively on students' behavior to minimize substance use and creating awareness on the disadvantages of premarital sexual activities.

$\begin{array}{ll}\text { Abbreviation } \\ \text { CSA } & \text { Central Statistical Agency } \\ \text { EDHS } & \text { Ethiopian Demographic and Health Survey } \\ \text { ETB } & \text { Ethiopian Birr } \\ \text { MDGs } & \text { Millennium Development Goals } \\ \text { NGO } & \text { Nongovernmental Organization } \\ \text { RH } & \text { Reproductive Health } \\ \text { SNNPR } & \text { Southern Nations, Nationalities, and People } \\ \text { STD } & \text { Region } \\ \text { STI } & \text { Sexually transmitted disease } \\ \text { UK } & \text { Sexually Transmitted Infection } \\ \text { UNICEF } & \text { United Kingdom } \\ \text { USA } & \text { United Nations Children's Emergency Fund } \\ \text { WHO } & \text { World Health Organization }\end{array}$

\section{Declarations}

\section{Competing Interests}

We declare that there are no conflicts of interest associated with this publication

\section{Authors' Contributions}

All authors participated in conception and the design of the study. W. A and N. D participated in the data collection. A. E analyzed the data and wrote the original script. All authors approved the manuscript for publication.

\section{Acknowledgements}

We would like to acknowledge Wachemo University for its unreserved financial support to conduct this research. Finally, we express our thanks to respondents and data collectors. 


\section{References}

[1] "Adolescent health - World Health Organization. available at https://www.who.int."

[2] J. Nicholson, "Risky Sexual Behaviour among Adolescents and Young Adults," University of North Carolina Chapel Hill, 2012.

[3] P. R. Bureau., " Meeting Young Women Reproductive and Sexual Needs. advocates for youth.," 2004.

[4] T. B. Teferra, A. N. Erena, and A. Kebede, "Prevalence of premarital sexual practice and associated factors among undergraduate health science students of Madawalabu University, Bale Goba, South East Ethiopia: institution based cross sectional study," Pan African medical journal, vol. 20, no. $1,2015$.

[5] A. J. Gage, and D. Meekers, "Sexual activity before marriage in sub-Saharan Africa," Social Biology, vol. 41, no. 1-2, pp. 44-60, 1994.

[6] N. Taffa, J. Sundby, C. Holm-Hansen, and G. Bjune, "HIV prevalence and socio-cultural contexts of sexuality among youth in Addis Ababa, Ethiopia," Ethiopian journal of health development, vol. 16, no. 2, pp. 139-145, 2002.

[7] A. Bogale, and A. Seme, "Premarital sexual practices and its predictors among in-school youths of shendi town, west Gojjam zone, North Western Ethiopia," Reproductive health, vol. 11, no. 1, pp. 49, 2014.

[8] Z. Mengistie, E. Wolie, E. Abawa, E. Ebre, and A. Adera, "Knowledge attitude and practice towards premarital sex and HIV/AIDS among Mizan-Tepi University students, south west Ethiopia," Sci J public Health, vol. 3, no. 4, pp. 592-599, 2015.

[9] G. Endazenaw, and M. Abebe, "Assessment of premarital sexual practices and determinant factors among high school students in West Shoa Zone, Oromia Regional State, Ethiopia," Sci J Public Health, vol. 3, no. 2, pp. 229-236, 2015.

[10] G. K. Behulu, K. T. Anteneh, and G. L. Aynalem, "Premarital sexual intercourse and associated factors among adolescent students in Debre-Markos town secondary and preparatory schools, north west Ethiopia, 2017," BMC research notes, vol. 12, no. 1, pp. 95, 2019.

[11] e. a. Akililu Alemu, "Premarital sexual practice and its associated factors among high school adolescents in kolfe keraniyo sub city, addis ababa, ethiopia: A cross sectional study," International Journal of Development Research, vol. 5 , no. 2, 2015.

[12] Y. Mulugeta, and Y. Berhane, "Factors associated with pre-marital sexual debut among unmarried high school female students in bahir Dar town, Ethiopia: crosssectional study," Reproductive health, vol. 11, no. 1, pp. 40, 2014.

[13] G. M. Kassa, E. B. Woldemariam, and N. A. Moges, "Prevalence of premarital sexual practice and associated factors among alamata high school and preparatory school adolescents, Northern Ethiopia," Global Journal of Medical Research, 2014.
[14] M. Akibu, F. Gebresellasie, F. Zekarias, and W. Tsegaye, "Premarital sexual practice and its predictors among university students: institution based cross sectional study," Pan African Medical Journal, vol. 28, no. 1, 2017.

[15] K. Beyene, L. Hinkosa, D. Bekele, and B. Demtsu, "Magnitude of premarital sexual practice and associated factors among adigrat high school students, ethiopia, a cross sectional study," Ethiopian Journal of Reproductive Health, vol. 11, no. 3, pp. 10-10, 2019.

[16] M. B. Selgado, "Premarital sexual practices and associated factors among high school students in Hawassa city in Ethiopia, 2018: Institutional-based cross sectional study design," International Journal of Scientific Reports, vol. 5, no. 8, pp. 207-212, 2019.

[17] Y. Berhane, Y. Mekonnen, E. Seyoum, L. Gelmon, and D. Wilson, "HIV/AIDS in Ethiopia-an epidemiological synthesis," Ethiopia HIV/AIDS Prevention \& Control Office (HAPCO) and Global AIDS Monitoring \& Evaluation Team (GAMET), 2008.

[18] E. Scholl, A. Burns, X. Gutiérrez, and J. Garache, "Assessment of youth reproductive health programs in Nicaragua," 2003.

[19] H. M. Bizuayehu, D. M. Abyu, and H. F. Demessie, "Assessment of time of sexual initiation and its associated factors among students in Northwest Ethiopia," Sci J Public Health, vol. 3, no. 1, pp. 10-8, 2015.

[20] A. S. Beyene, and A. M. Seid, "Prevalence of premarital sex and associated factors among out-of-school youths (aged 1524) in Yabello town, Southern Ethiopia: A community based cross-sectional study," The Pharma Innovation, vol. 3, no. 10, Part A, pp. 10, 2014.

[21] J. L. Morris, and H. Rushwan, "Adolescent sexual and reproductive health: The global challenges," International Journal of Gynecology \& Obstetrics, vol. 131, pp. S40-S42, 2015.

[22] "Hossana town education office," 2018.

[23] A. Seme, and D. Wirtu, "Premarital sexual practice among school adolescents in Nekemte Town, East Wollega," Ethiopian Journal of Health Development, vol. 22, no. 2, pp. 167-173, 2008.

[24] L. Oljira, Y. Berhane, and A. Worku, "Pre-marital sexual debut and its associated factors among in-school adolescents in eastern Ethiopia," BMC public health, vol. 12, no. 1, pp. 375, 2012.

[25] M. Abebe, A. Tsion, and F. Netsanet, "Living with parents and risky sexual behaviors among preparatory school students in Jimma zone, South west Ethiopia," African health sciences, vol. 13 , no. 2 , pp. 498-506, 2013.

[26] A. Tololu, S. Belda, and B. Worku, "Premarital sexual practice and associated factors among robe TVET students at robe town, bale zone, Oromia region, southeast Ethiopia, 2016," MOJ Public Health, vol. 5, no. 6, pp. 193-203, 2017.

[27] F. H. Tolera, E. Girma, A. Mamo, and Z. K. Babure, "Risky sexual behaviors and associated factors among high and preparatory school youth, East Wollega, Ethiopia, 2017: A cross-sectional study design," Journal of Public Health and Epidemiology, vol. 11, pp. 1-12, 2019. 
[28] F. Mazengia, and A. Worku, "Age at sexual initiation and factors associated with it among youths in North East Ethiopia," Ethiopian Journal of Health Development, vol. 23, no. 2, 2009.

[29] M.-L. Wong, R. K.-W. Chan, D. Koh, H.-H. Tan, F.-S. Lim, S. Emmanuel, and G. Bishop, "Premarital sexual intercourse among adolescents in an Asian country: multilevel ecological factors," Pediatrics, vol. 124, no. 1, pp. e44-e52, 2009.

[30] M. Tilahun, and G. Ayele, "Factors associated with age at first sexual initiation among youths in Gamo Gofa, south west Ethiopia: a cross sectional study," BMC Public Health, vol. 13 , no. 1, pp. $622,2013$. 